\title{
Effect of Tissue Transglutaminase on Steroid Resistance in T-Cell Acute Lymphoblastic Leukemia
}

\author{
HYUN JOO JUNG ${ }^{1}$, EUN HEE HAN ${ }^{1}$, IN KEUN JANG ${ }^{2}$, SEUNG-HYUN YOON ${ }^{3}$ and JUN EUN PARK ${ }^{1}$ \\ ${ }^{1}$ Department of Pediatrics, Ajou University Hospital, \\ Ajou University School of Medicine, Suwon, Republic of Korea; \\ ${ }^{2}$ Biomedical Research Institute, Lifeliver Co., Ltd., Yongin, Republic of Korea; \\ ${ }^{3}$ Department of Physical Medicine, Ajou University Hospital, \\ Ajou University School of Medicine, Suwon, Republic of Korea
}

\begin{abstract}
Aim: To improve survival in patients with glucocorticoid-resistant T-cell acute lymphoblastic leukemia (T-ALL), it is critical to develop new therapeutic strategies to overcome steroid resistance. Materials and Methods: Biochemical and molecular methodologies were used to evaluate whether tissue transglutaminase (TG2) confers steroid resistance in T-ALL. Results: T-ALL cells were found to express elevated levels of TG2. Models of steroid-adapted subclones of T-ALL cell lines which were notably less sensitive to steroids than the parental cells. The steroid-adapted subclones showed increased TG2 expression and nuclear factor- $\mathrm{kB}(N F-\kappa B)$ activity compared to $T$-ALL parental cells. Inhibition of TG2 suppressed steroid resistance and improved steroid cytotoxicity in steroid-adapted subclones of T-ALL in association with reduced $N F-k B$ activity. Conclusion: TG2 may serve as a new target to overcome steroid resistance in $T$-ALL.
\end{abstract}

Acute lymphoblastic leukemia (ALL) is a malignant disorder of lymphoid progenitor cells that is diagnosed in children and adults. T-Cell acute lymphoblastic leukemia (T-ALL) represents $15 \%$ of childhood and $25 \%$ of adult ALL cases. Although long-term survival rates approach $90 \%$ with risk-directed intensive chemotherapy, as many as $30 \%$ of childhood cases and approximately $50 \%$ of adult cases will relapse (1-3). Regardless of the type of ALL,

Correspondence to: Jun Eun Park, Department of Pediatrics, Ajou University Hospital, Ajou University School of Medicine, 164 World Cup-ro, Yeongtong-gu, Suwon 16499, Republic of Korea. Tel: +82 0312195160, Fax: +82 0312195169, e-mail: pedpje@ajou.ac.kr

Key Words: Tissue transglutaminase, steroid resistance, T-cell acute lymphoblastic leukemia. steroids constitute critical components of multi-agent combined chemotherapy regimens used in ALL treatments. Steroids induce apoptosis of hematological cells by binding to glucocorticoid receptors (GR) in the cytoplasm. GRs interact with glucocorticoid-response elements to induce proapoptotic gene transcription as well as with transcription factors such as nuclear factor- $\mathrm{kB}(\mathrm{NF}-\mathrm{kB})$ or activating protein-1. Both pathways induce cell-cycle arrest and apoptosis. Prolonged steroid exposure induces upregulation of GRs in ALL cells and the responsive genes have been functionally linked to three major pathways: Glucose metabolism, NF-kB signaling, and cell proliferation and survival (4-6). Although most patients with ALL respond well to steroids, some develop secondary resistance after prolonged steroid therapy. Steroid resistance is common upon relapse and leads to significantly poorer outcomes (7), with B-cell acute lymphoblastic leukemia (B-ALL) and T-ALL exhibiting divergent mechanisms of resistance. For instance, T-ALL is a more biologically resistant disease $(8,9)$. Intervention strategies to reverse steroid resistance will definitely improve outcomes in such patients.

Recent studies report that tissue transglutaminase (TG2) is associated with resistance to chemotherapy in some cancer types (10-12). TG2 is a multi-functional enzyme that catalyzes the formation of inter- or intra-molecular bonds with a wide distribution in various tissues. It has multiple physiological functions in normal tissues and is associated with cancer cell survival and drug resistance in cancer cells (13). Certain studies suggest that TG2 overexpression enhances cancer cell survival via the association between TG2 and NF-kB expression $(12,14,15)$.

In the present study, we explored the link between TG2 expression and cell survival in steroid-resistant T-ALL with the aim of developing a novel strategy to overcome steroid resistance in T-ALL. 


\section{Materials and Methods}

Cell lines and cell maintenance. The human T-ALL cell lines Jurkat, MOLT-4, and CCRF-CEM were obtained from the American Type Culture Collection (Manassas, VA, USA). T-ALL cell lines were cultured in complete RPMI 1640 medium (LM011-51; Welgene, Seoul, Republic of Korea) containing $10 \%$ heat-inactivated fetal bovine serum (Gibco/Thermo Fisher Scientific, Gaithersburg, MD, USA), and $1 \%$ penicillin-streptomycin (Gibco).

Reagents. Prednisolone was obtained from the pharmacy at Ajou University Hospital. Different concentrations of prednisolone were used to generate steroid-adapted (SA) T-ALL cells and to compare the cell viability of parental cells and SA cells of T-ALL. To generate the SA cells, we cultured the T-ALL cell lines in slowly increasing prednisolone concentrations over 4 months. The final maximum prednisolone concentration at which each T-ALL cell no longer proliferated was $100 \mu \mathrm{g} / \mathrm{ml}$ for Jurkat, $60 \mu \mathrm{g} / \mathrm{ml}$ for MOLT-4, and 70 $\mu \mathrm{g} / \mathrm{ml}$ for CCRF-CEM. Monodansyl cadaverine (MDC) was purchased from Sigma-Aldrich (Buchs, Switzerland). We used MDC as a TG2-specific inhibitor. To investigate the effect of TG2 inhibition on NF-kB activity and steroid resistance in steroid-adapted T-ALL cells, we cultured SA T-ALL cells with $150 \mu \mathrm{M}$ MDC for $72 \mathrm{~h}$.

Immunofluorescence analysis. Immunofluorescence was performed on human T-ALL cell lines. Samples were fixed with ice-cold methanol and incubated with 10\% goat serum (Gibco) for $45 \mathrm{~min}$ for blocking. They were then exposed to 1:300 TG2 antibodies (GeneTex, Irvine, CA, USA) overnight at $4^{\circ} \mathrm{C}$. Cells were treated with 1:300 DyLight594 conjugate rabbit IgG antibody (Bethyl Laboratories, Montgomery, TX, USA) and DAPI Fluoromounting medium (SouthernBiotech, Birmingham, AL, USA) for 1 hour at room temperature. At least five randomly selected regions for slides were analyzed and a minimum of 500 nuclei were counted for each sample. Samples were analyzed on a Nikon A1 confocal microscope (Nikon, Tokyo, Japan) in accordance with established methods in the instruction manual (Ver.4.10).

Immunoblot analysis. Cell lysate proteins obtained using commercially available cell lysis buffer (Biosesang, Gyeonggi-do, Republic of Korea) were solubilized with $25 \mathrm{mM}$ Tris, $195 \mathrm{mM}$ glycerine, $1 \%$ sodium dodecyl sulfate, and 1x Tris-glycine-SDS running buffer (Elpis Biotech, Inc., Daejeon, Republic of Korea) and electrophoresed on a $10 \%$ Trisglycine-SDS gel. Proteins were transferred onto nitrocellulose membranes and probed with 1:1000 TG2-specific primary antibodies (GeneTex, Irvine, CA, USA) followed by 1:5000 goat anti-rabbit IgG horseradish peroxidase-conjugated secondary antibodies (Santa Cruz Biotechnology, Dallas, TX, USA). Proteins were visualized by enhanced chemiluminescence (GE Healthcare, Little Chalfont, UK).

TG2 enzymatic activity assay. The levels of TG2 enzymatic activity were determined using the TG2-Covtest TG2-specific colorimetric assay kit (Novus Biologicals, Centennial, CO, USA). In this assay, color intensity is directly proportional to the TG2 activity in the sample. All test protocols were performed according to the manufacturer's instructions. This assay was performed as previously described by Jung et al. (12).

Colorimetric cell viability assay. Cell viability of T-ALL cell lines, Jurkat, MOLT-4, and CCRF-CEM, treated with TG2 inhibitor or different concentrations of steroid was evaluated. Viability was assessed using CellTiter-Blue ${ }^{\circledR}$ Assay kit (Promega, Madison, WI, USA) according to the manufacturer's instructions. The signal was measured at $560 \mathrm{Ex} / 590 \mathrm{Em}$ using a colorimetric plate reader equipped with Gen5 software (BioTek Instruments, Inc., Winooski, VT, USA). Dose-response curves were analyzed based on results from the cell viability assays of cells treated without steroids.

Flow cytometry. Leukemia cells treated with or without steroid were washed with cold Hank's balanced salt solution, filtered with a 40 $\mu \mathrm{m}$ cell strainer and incubated with $0.1 \mu \mathrm{g} / \mathrm{ml}$ rhodamine 123 (Rh123; Enzo, Farmingdale, NY, USA) at a density of $106 \mathrm{cells} / \mathrm{ml}$. Samples were analyzed using BD FACS Aria III (BD, San Jose, CA, USA). All assays were performed in triplicate.

$N F-k B$ activity assay. All steps of nuclear extraction from leukemia cells were performed according to the manufacturer's instructions and the buffers were purchased from Active Motif (Carlsbad, CA, USA). Nuclear extracts were used in the assay for NF-kB p50, p65, p52, c-REL, or RELB DNA-binding activity using an enzymelinked immunosorbent assay (ELISA) according to the Active Motif TransAM ${ }^{\circledR}$ NFkB Family Kit protocol (Active Motif). The signal was measured using a spectrophotometer equipped with SoftMax ${ }^{\circledR}$ Pro software (Molecular Devices, San Jose, CA, USA).

Statistical analysis. Analysis was performed using PASW Statistics 18 (SPSS Inc., Chicago, IL, USA). Statistical analysis was carried out for continuous variables using $t$-test or ANOVA test. $p$-Values of less than 0.05 were considered statistically significant.

\section{Results}

TG2 expression in T-ALL cells. We first examined TG2 expression in different human T-ALL cell lines: Jurkat, MOLT4, and CCRF-CEM. Confocal microscopy showed TG2 expression in the cytoplasm of T-ALL cells (Figure 1A). Further immunoblot analysis revealed the constitutive expression of TG2 in three different T-ALL cell lines (Figure 1B). TG2 functional enzymatic activity assay performed on three different T-ALL cell lines also indicated TG2 enzymatic activity in TALL (Figure 1C). To summarize, the results show that TG2 is expressed and has functional enzymatic activity in T-ALL cells.

Figure 1. Tissue transglutaminase (TG2) is expressed in T-cell acute lymphoblastic leukemia (T-ALL). (A) Immunofluorescence confocal microscope images show the localization of TG2 in the cytoplasm of $T$ ALL cell lines Jurkat, MOLT-4, and CCRF-CEM cells. Arrows in each panel indicate representative signals of TG2. (B) Immunoblot analysis of TG2 on three different T-ALL cell lines: Jurkat, MOLT-4, and CCRFCEM. The Jeko-1 mantle cell lymphoma cell line was used as a positive control. Glyceraldehyde 3-phosphate dehydrogenase (GAPDH) was used as a loading control. (C) The enzymatic activity of TG2 in three different T-ALL cell lines was determined using the TG2-Covtest TG2specific colorimetric assay (Novus Biologicals). Jeko-1 cell extracts were used as positive controls. Data are means \pm standard deviation of five independent experiments performed. 


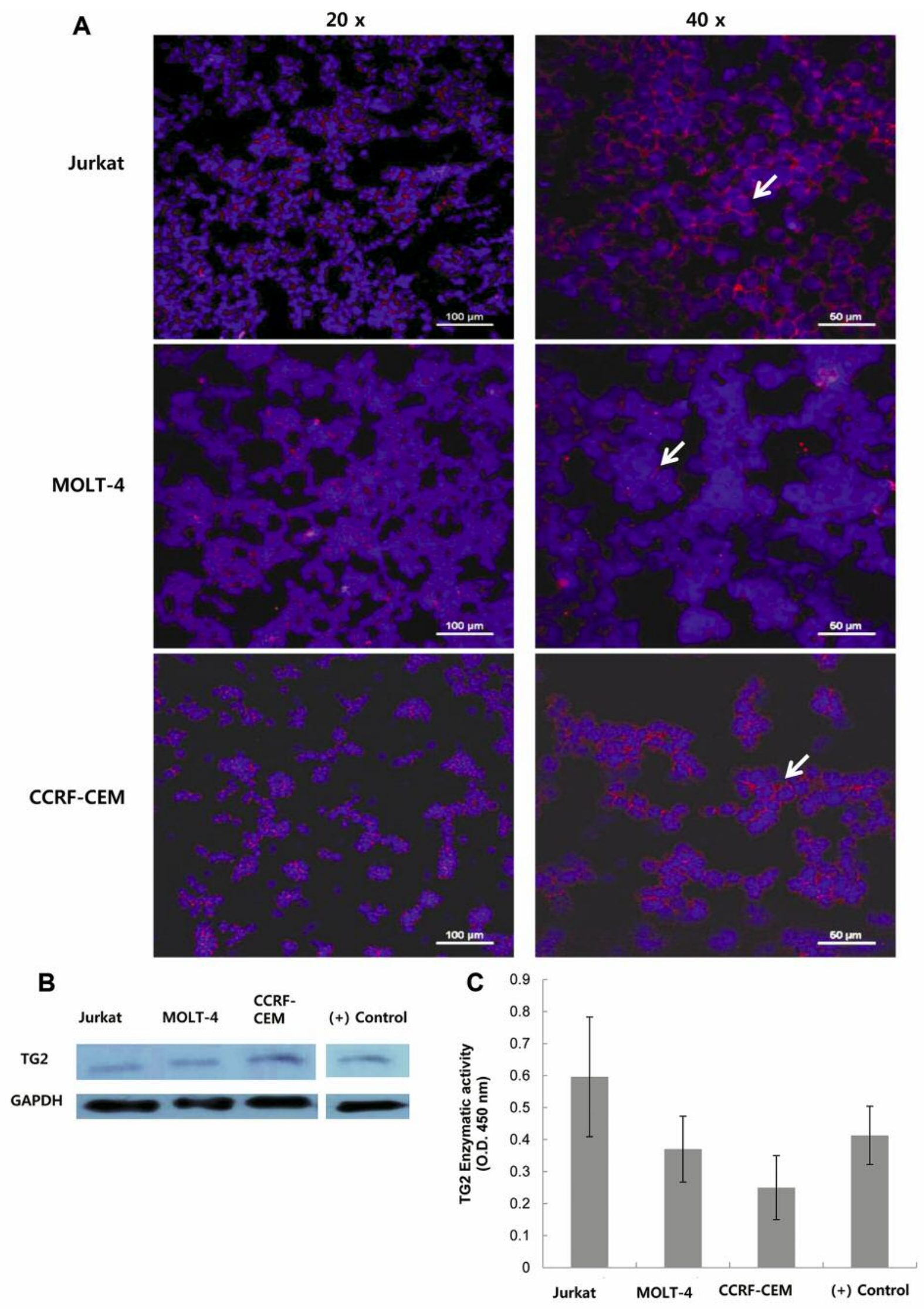




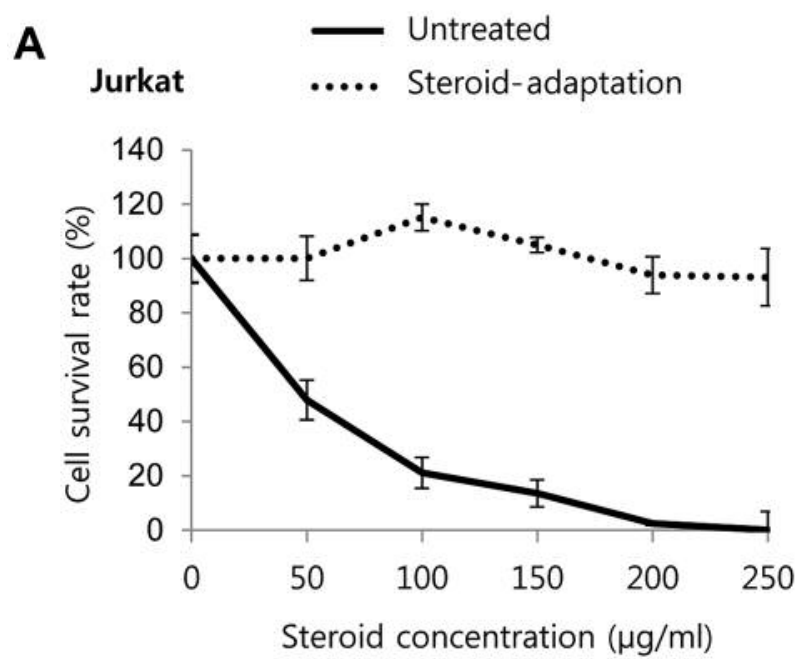

MOLT-4

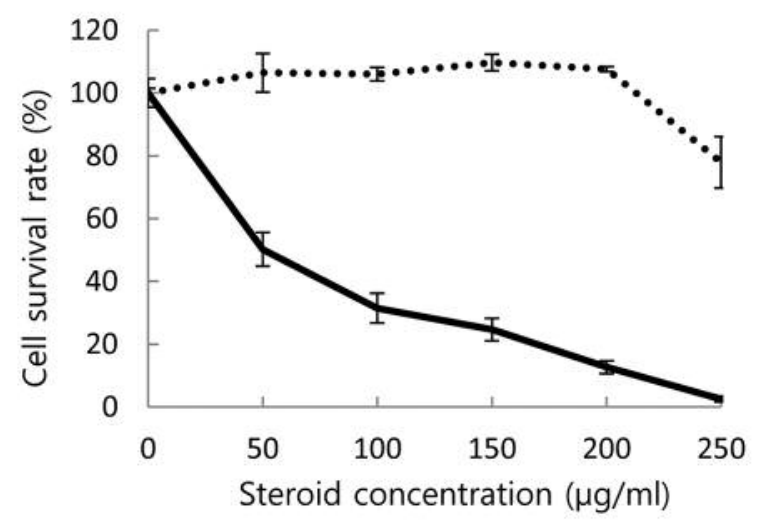

B

Jurkat

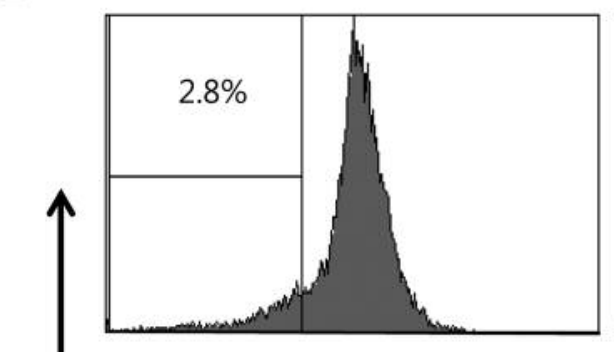

Untreated

Steroid-adaptation

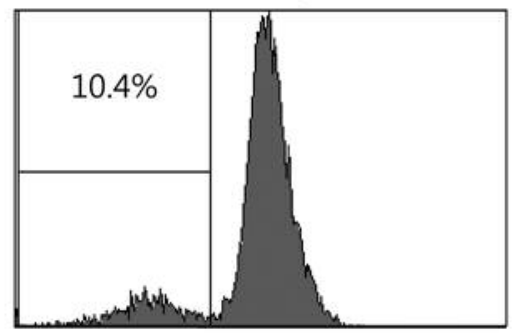

MOLT-4



Untreated

Steroid-adaptation



Rhodamine 123
Figure 2. Steroid-adapted (SA) T-cell acute lymphoblastic leukemia (T-ALL) cells are more resistant to steroids than their parental cells. (A) Higher steroid concentrations are required for cytotoxic effects in $S A$ Cells compared to their parental cells. SA and parental T-ALL cell lines Jurkat, MOLT-4 and CCRF-CEM were tested for steroid sensitivity. Cells were cultured for $72 h$ with serially diluted prednisolone as indicated from a maximum concentration of $250 \mu \mathrm{g} / \mathrm{ml}$. Cell viability was determined by a CellTiter-Blue ${ }^{\circledR}$ fluorometric assay (Promega) and was indicated as a ratio compared to cell viability without treatment. The results show the mean \pm standard deviation of riplicates. (B) Steroid adaptation increased the population of T-ALL with low rhodamine 123 accumulation, i.e. with chemoresistance. Representative histograms show FACS analysis of rhodamine 123 accumulation in SA subclones and parental T-ALL cell lines.

\section{CCRF-CEM}



CCRF-CEM



Untreated

Steroid-adaptation

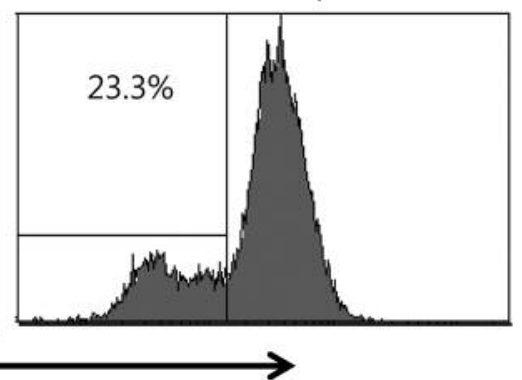




\section{A}

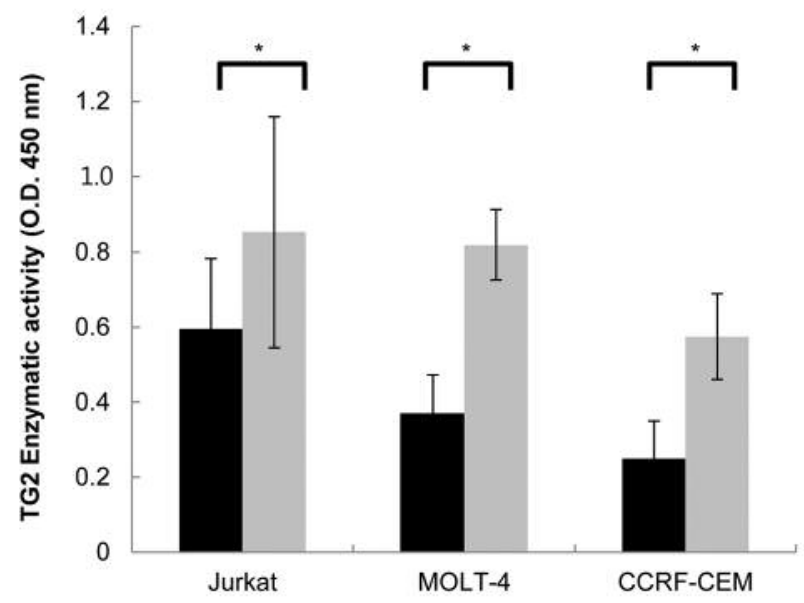

Figure 3. Steroid adaptation increases tissue transglutaminase (TG2) activity and nuclear factor- $\mathrm{k} B(N F-\kappa B)$ expression in $T$-cell acute lymphoblastic leukemia (T-ALL) cells. (A) Steroid-adapted (SA) T-ALL subclones express TG2 more than their parental cells. The enzymatic activity of TG2 in SA and parental T-ALL cell lines, Jurkat and CCRFCEM, was determined using the TG2-Covtest TG2-specific colorimetric assay (Novus Biologicals). The results show the mean \pm standard deviation of triplicates. $*$ Significantly different at $p<0.05$ by unpaired $t$-test. (B) Steroid adaptation increases $N F-k B D N A$-binding activity in $T$-ALL cells. Nuclear extracts from the T-ALL cell lines Jurkat and CCRF-CEM that were untreated or adapted with steroids were analyzed using enzyme-linked immunosorbent assay colorimetric assays (optical density, $450 \mathrm{~nm}$ ) to evaluate $N F-\kappa B D N A$-binding activities.

Generation of SA T-ALL cells. To investigate the mechanisms of resistance to steroids in T-ALL, we adapted the T-ALL cell lines to increasing steroid concentrations. SA cell lines were generated by continuous culture of parental cell lines in increasing steroid concentrations, up to a maximum concentration that inhibited cell proliferation. The final maximum steroid concentrations were determined for each cell line. From a set of previously characterized steroidsensitive T-ALL cell lines, we successfully derived steroidresistant subclones of T-ALL cell lines (Figure 2A); these steroid resistance-induced subclones were termed as SA cells. To determine the mechanism of steroid resistance acquisition of SA cells, we analyzed changes in the fractions exhibiting low Rh123 accumulation, which indicates drugresistant cells, before and after steroid adaptation. Flow cytometric analysis showed that the proportion of cells with low Rh123 accumulation was significantly increased after steroid adaptation (Figure 2B). These results suggest that steroid adaptation induces steroid resistance in T-ALL cells. Steroid adaptation affects TG2 and NF-kB activity in T-ALL.
B

- Untreated

= Steroid-adaptation
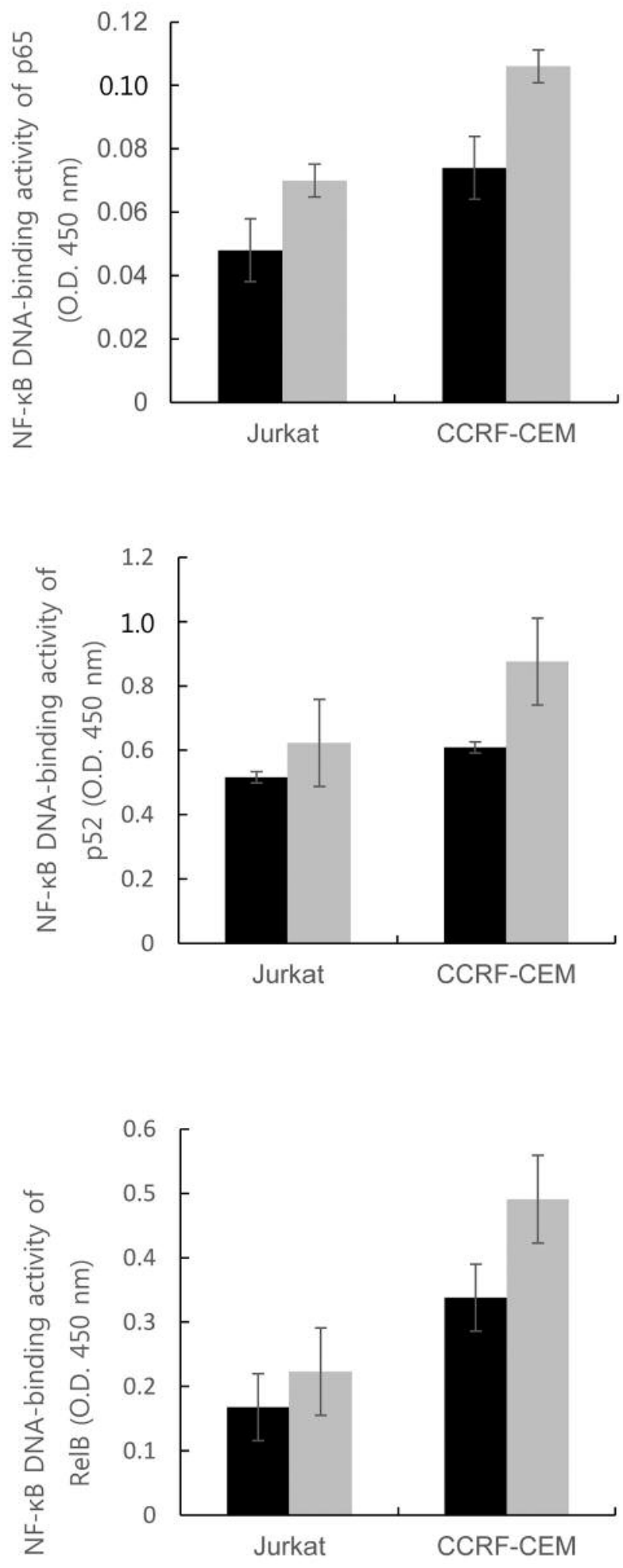
Drug-resistant cells express higher levels of TG2 than their drug-sensitive parental cells and TG2 expression is associated with NF-KB activation in solid and hematological malignant cells $(10,12,16)$. To determine the effects of steroid adaptation on TG2 and NF-kB activity in T-ALL, we first measured TG2 enzymatic activities of different untreated parental and SA T-ALL cell lines using colorimetric assay kits. Figure 3A shows that steroid adaptation increased TG2 enzymatic activity in T-ALL cells. We also analyzed the NF$\mathrm{kB}$ DNA-binding activities of untreated and SA T-ALL cells. The DNA-binding activities of NF-kB transcription factor p65, p52, and RELB significantly increased after steroid adaptation in Jurkat and CCRF-CEM cells (Figure 3B). These data clearly demonstrate that steroid adaptation induces TG2 and NF-kB expression in T-ALL.

TG2 inhibition reduces steroid resistance in SA T-ALL. We hypothesized that TG2 inhibition reduced NF-kB activity and reduced steroid resistance in SA T-ALL. We first treated SA T-ALL cells with a specific TG2 inhibitor, MDC. Subsequently, we measured TG2 enzymatic activity of untreated parental cells, SA cells, and TG2 inhibitor-treated SA cells in three different T-ALL cell lines. TG2 enzymatic activities of T-ALL cells significantly increased after steroid adaptation; however, they significantly decreased in response to MDC treatment (Figure 4A). Furthermore, we evaluated the DNA-binding activity of NF-KB transcription factors in TG2 inhibitor-treated SA T-ALL. The DNA-binding activity of NF$\mathrm{\kappa B}$ transcription factor $\mathrm{p} 65, \mathrm{p} 52$, and RelB were significantly reduced after TG2 inhibitor-mediated TG2 inhibition in TALL cell lines (Figure 4B). These results demonstrate that TG2 inhibition resulted in the inhibition of NF-KB activities in T-ALL. To evaluate the effect of TG2 inhibition on steroid resistance in T-ALL, the cell viability of untreated parental cells, SA cells, and MDC-treated SA cells was measured in three different T-ALL cell lines using a fluorometric assay. TG2 inhibition improved the steroid cytotoxic effects of SA cells compared with MDC-untreated SA cells (Figure 4C).

\section{Discussion}

T-ALL is a major subtype of ALL, with survival rates being significantly worse than those for B-ALL in both children and adults $(1,17,18)$. Improved outcomes can be attributed to optimal risk-directed therapies; nevertheless, the response to steroid treatment remains a very important indicator of prognosis in patients with ALL $(2,4)$. Some patients with ALL experience primary steroid resistance and patients with steroid-sensitive disease almost exclusively develop secondary resistance after prolonged steroid therapy $(4,7)$. Recently, early T-cell precursor (ETP)-ALL has emerged as a peculiar biological subtype of T-ALL. ETP-ALL presents poor survival rates after failure of primary remission or allogeneic hematopoietic stem cell transplantation $(19,20)$. The development of new treatment targets is an important need in overcoming this steroid resistance in T-ALL including ETP-ALL.

TG2 is a member of the transglutaminase family that is related to multiple cellular processes such as wound healing, cell survival, and apoptosis $(15,21)$. The expression of TG2 was previously determined in various solid or hematologic malignant cells $(12,14,16)$. Certain studies show that TG2 overexpression is associated with drug resistance in cancer cells and TG2 and subsequent NF-KB activation may constitute a feasible new target to overcome chemotherapy resistance in malignant cells $(11,12,16)$.

We hypothesized that steroid-resistant T-ALL cells expressed TG2 and that the modification of TG2 expression would alter NF-kB activation and affect cell survival in steroid-resistant T-ALL cells. To the best of our knowledge, this study is the first to demonstrate that TG2 was expressed in T-ALL cells (Figure 1). To test our hypothesis, we generated SA T-ALL cells that developed steroid resistance through prolonged steroid treatment (Figure 2). Acquired steroid resistance after prolonged steroid therapy is more common and influences the care of patients with T-ALL; therefore, we devised a new experimental method to generate the SA T-ALL cells in this study. We cultivated T-ALL cell lines in slowly increasing steroid concentrations, up to a maximum concentration that inhibited cell proliferation in each. We refer to these cultured cells as 'steroid-adapted' instead of 'steroid-resistant' cells, as they were adapted to a

Figure 4. Transglutaminase (TG2) inhibition suppresses nuclear factor$\kappa B(N F-k B)$ activity and steroid resistance in steroid-adapted (SA) Tcell acute lymphoblastic leukemia (T-ALL) cells. A: SA T-ALL cells were treated with TG2-specific inhibitor MDC (150 $\mu M$ for $72 h)$. The enzymatic activity of TG2 on SA cells, MDC-treated SA (SA TG2 inhibition), and parental T-ALL cell lines was determined using the TG2-Covtest TG2-specific colorimetric assay (Novus Biologicals). The results show the mean \pm standard deviation $(S D)$ of triplicates. *Significantly different at $p<0.05$ by unpaired t-test. B: Inhibition of $T G 2$ reduced $N F-K B$ DNA-binding activity in SA T-ALL cells. Nuclear extracts from T-ALL cell lines Jurkat and CCRF-CEM untreated, adapted to steroids, or treated with MDC after steroid adaptation were analyzed using enzyme-linked immunosorbent assay colorimetric assays (optical density, $450 \mathrm{~nm}$ ) to evaluate $N F-k B$ DNA-binding activity. $C$ : $T G 2$ inhibition increased the cytotoxic effects of steroid on SA T-ALL cells. SA, TG2 inhibitor-treated SA (SA TG2 inhibition) and parental T$A L L$ cell lines, Jurkat, MOLT-4 and CCRF-CEM, were tested for the steroid sensitivity. Cells were cultured for $72 \mathrm{~h}$ with prednisolone, at serial dilution as indicated, from a maximum concentration of 250 $\mu \mathrm{g} / \mathrm{ml}$. Cell viability was determined by CellTiter-Blue ${ }^{\circledR}$ fluorimetric assay (Promega) and is indicated as a ratio compared to cell viability without treatment. The results show the mean $\pm S D$ of triplicates. *Significantly different at $p<0.05$ by ANOVA test. 




B

- Untreated

= Steroid-adaptation

口 SA_TG2 inhibition
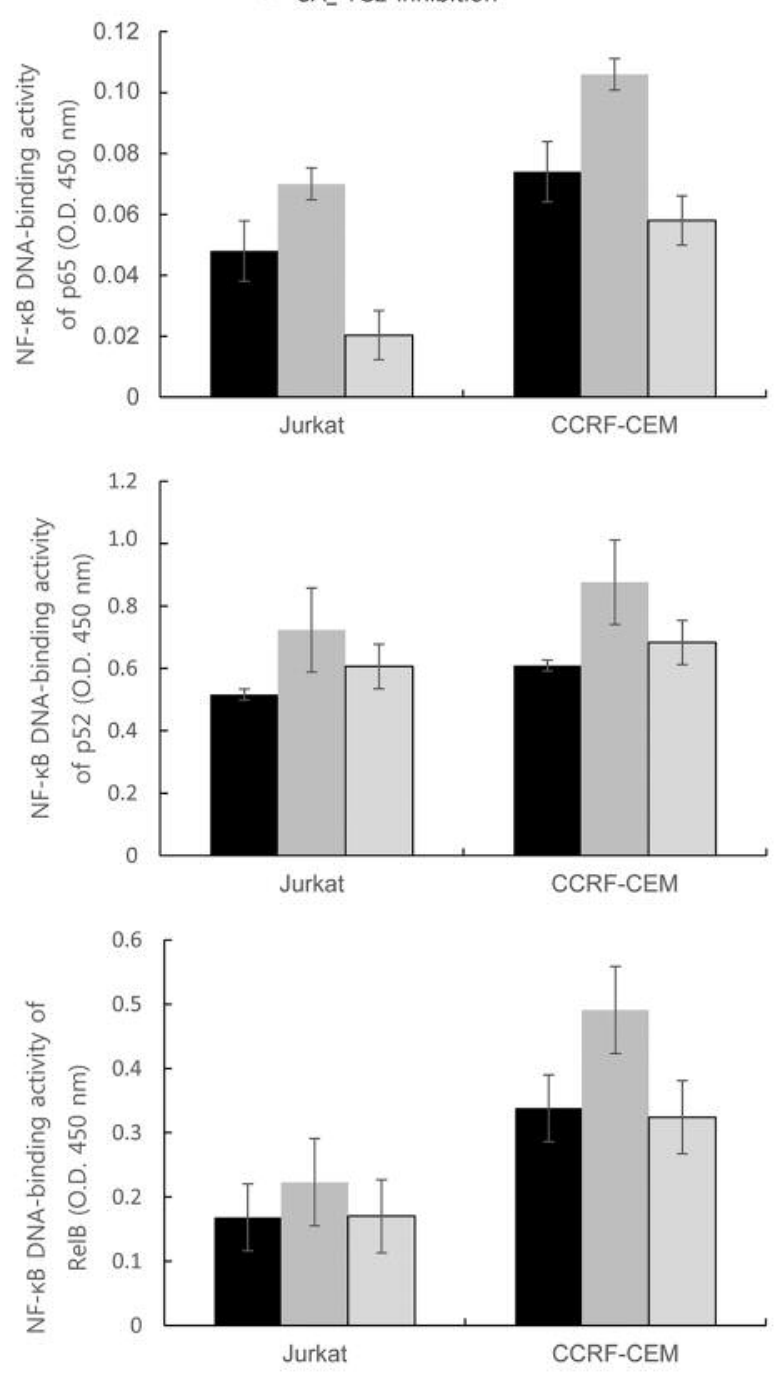

C



MOLT-4

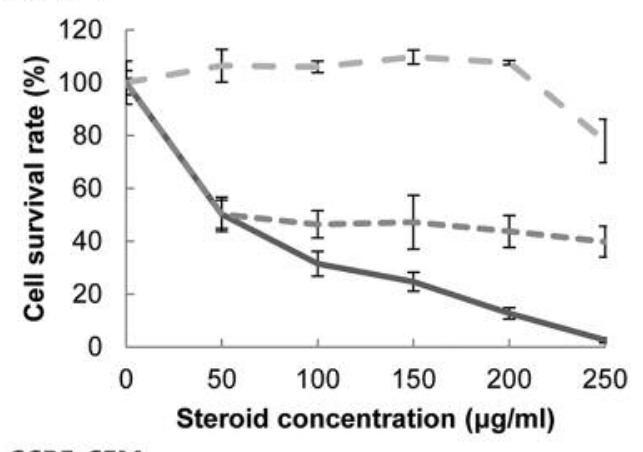

\section{CCRF-CEM}

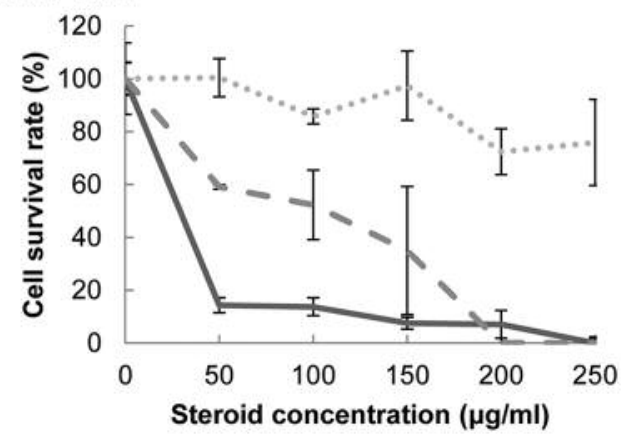


steroid-rich cell culture environment and gained resistance to steroids via a gradual increase in steroid concentration over a long period of time. Rh123 is a substrate for the adenosine triphosphate (ATP)-binding cassette (ABC) transporter ABCB1 (P-glycoprotein); ABCB1 acts as a unidirectional drug efflux pump in tumor cells (22-24). Decreased Rh123 accumulation (high ABCB1 expression or activity) indicates not only inactive mitochondria, suggesting a possible quiescent state of the cells, but also high efflux activity of ABCB1, which can lead to drug resistance $(24,25)$. Previous studies reported that a major population of human $\mathrm{T}$ lymphocytes expressed functional $\operatorname{ABCB} 1(26,27)$. In this study, we showed that steroid adaptation induced a significant increase of T-ALL cells with low Rh123 accumulation. These results suggest that steroid adaptation leads to an increase in the cell proportion exhibiting quiescence and steroid resistance in T-ALL.

Prolonged steroid exposure induces the up-regulation of GRs in the cytoplasm of leukemia cells and ultimately leads to the prolongation of cell proliferation and survival, as well as the constitutive overexpression of NF- $\mathrm{KB}$ signaling in ALL cells $(4,5)$. NF- $\mathrm{kB}$ is a well-known transcriptional factor involved in various cellular responses including apoptosis, cell cycle, and oncogenesis. Various studies have identified a link between NF-kB and malignancy; the inhibition of NF-kB activation has been attracting attention as a therapeutic target (28-30). Certain studies suggest that the NF- $\mathrm{kB}$ expression of cancer cells is modulated by TG2 activity $(12,16,31,32)$. In this study, we showed that SA TALL cells expressed higher levels of TG2 and NF-kB compared to their parental steroid-sensitive cells (Figure 3 ). In addition, we revealed that specific TG2 inhibitors suppressed NF-kB expression and enhanced SA T-ALL cells to steroid cytotoxicity (Figures 3 and 4 ). To the best of our knowledge, this study is the first to describe the link between NF-kB and TG2 in T-ALL and to suggest that the inhibition of $\mathrm{NF}-\mathrm{kB}$ activation by TG2 modulation may represent a potential therapeutic target of steroid-resistant T-ALL.

TG2 is a calcium-dependent enzyme; MDC acts as a specific TG2 inhibitor by exploiting this calcium dependence (33). Calcium blockers have been widely used in various cardiovascular diseases and have been proven safe. Furthermore, some studies suggested that certain calcium blockers may be an alternative drug in combined adjuvant chemotherapy $(34,35)$. Our next step will be to investigate the role of calcium blockers in overcoming steroid resistance in T-ALL.

In conclusion, the present study is the first to demonstrate the contribution of TG2 expression to NF-kB and steroid resistance in T-ALL. This study provides evidence for a promising new therapeutic target to overcome treatmentrelated steroid resistance and improve survival rates in patients with T-ALL.

\section{Conflicts of Interest}

None of the Authors have any conflict of interest in regard to this study.

\section{Authors' Contributions}

HJJ designed the study and wrote the article; EHH performed experiments; IKJ reviewed the data and the article; SEY revised the article; JEP guided the research and wrote the article.

\section{Acknowledgements}

This work was supported by the new faculty research fund of Ajou University School of Medicine and the National Research Foundation of Korea grant funded by the Korean government (MSIP) (grant number 2015053392). We would like to thank Editage (www.editage.co.kr) for English language editing.

\section{References}

1 Pui CH, Robison LL and Look AT: Acute lymphoblastic leukaemia. Lancet 371(9617): 1030-1043, 2008. PMID: 18358930. DOI: 10.1016/S0140-6736(08)60457-2

2 Pui $\mathrm{CH}$ and Evans WE: Treatment of acute lymphoblastic leukemia. N Engl J Med 354(2): 166-178, 2006. PMID: 16407512. DOI: $10.1056 /$ NEJMra052603

3 Hyery K: Advances in the treatment of childhood acute lymphoblastic leukemia. Clin Pediatr Hematol Oncol 26(1): 1226, 2019. DOI: $10.15264 /$ cpho.2019.26.1.12

4 Inaba $\mathrm{H}$ and Pui CH: Glucocorticoid use in acute lymphoblastic leukaemia. Lancet Oncol 11(11): 1096-1106, 2010. PMID: 20947430. DOI: $10.1016 / \mathrm{S} 1470-2045(10) 70114-5$

5 Tissing WJ, den Boer ML, Meijerink JP, Menezes RX, Swagemakers S, van der Spek PJ, Sallan SE, Armstrong SA and Pieters R: Genomewide identification of prednisolone-responsive genes in acute lymphoblastic leukemia cells. Blood 109(9): 39293935, 2007. PMID: 17218380. DOI: 10.1182/blood-2006-11056366

6 Bedewy AM, El-Maghraby SM, Kandil NS and El-Bendary WR: The prognostic value of glucocorticoid receptors for adult acute lymphoblastic leukemia. Blood Res 50(4): 235-241, 2015. PMID: 26770951. DOI: $10.5045 / \mathrm{br} .2015 .50 .4 .235$

7 Klumper E, Pieters R, Veerman AJ, Huismans DR, Loonen AH, Hahlen K, Kaspers GJ, van Wering ER, Hartmann R and Henze G: In vitro cellular drug resistance in children with relapsed/ refractory acute lymphoblastic leukemia. Blood 86(10): 38613868, 1995. PMID: 7579354. DOI: 10.1182/blood.v86. 10.3861.bloodjournal86103861

8 Weng AP, Ferrando AA, Lee W, Morris JPt, Silverman LB, Sanchez-Irizarry C, Blacklow SC, Look AT and Aster JC: Activating mutations of NOTCH1 in human T-cell acute lymphoblastic leukemia. Science 306(5694): 269-271, 2004. PMID: 15472075. DOI: 10.1126/science. 1102160

9 Shah DS and Kumar R: Steroid resistance in leukemia. World J Exp Med 3(2): 21-25, 2013. PMID: 24520542. DOI: 10.5493/ wjem.v3.i2.21

10 Mehta K, Fok J, Miller FR, Koul D and Sahin AA: Prognostic significance of tissue transglutaminase in drug-resistant and 
metastatic breast cancer. Clin Cancer Res 10(23): 8068-8076, 2004. PMID: 15585642. DOI: 10.1158/1078-0432.CCR-04-1107

11 Lee J, Yakubov B, Ivan C, Jones DR, Caperell-Grant A, Fishel M, Cardenas $\mathrm{H}$ and Matei D: Tissue transglutaminase activates cancer-associated fibroblasts and contributes to gemcitabine resistance in pancreatic cancer. Neoplasia 18(11): 689-698, 2016. PMID: 27792935. DOI: 10.1016/j.neo.2016.09.003

12 Jung HJ, Chen Z, Wang M, Fayad L, Romaguera J, Kwak LW and McCarty N: Calcium blockers decrease the bortezomib resistance in mantle cell lymphoma via manipulation of tissue transglutaminase activities. Blood 119(11): 2568-2578, 2012. PMID: 22294726. DOI: 10.1182/blood-2011-09-377598

13 Zhang J, Wang S, Huang W, Bennett DA, Dickson DW, Wang D and Wang R: Tissue transglutaminase and its product isopeptide are increased in Alzheimer's disease and Appswe/Ps1de9 double transgenic mice brains. Mol Neurobiol 53(8): 5066-5078, 2016. PMID: 26386840. DOI: 10.1007/s12035-015-9413-x

14 Mangala LS, Fok JY, Zorrilla-Calancha IR, Verma A and Mehta K: Tissue transglutaminase expression promotes cell attachment, invasion and survival in breast cancer cells. Oncogene 26(17): 2459-2470, 2007. PMID: 17043648. DOI: 10.1038/sj.onc.1210035

15 Song H, Kim BK, Chang W, Lim S, Song BW, Cha MJ, Jang Y and Hwang KC: Tissue transglutaminase 2 promotes apoptosis of rat neonatal cardiomyocytes under oxidative stress. J Recept Signal Transduct Res 31(1): 66-74, 2011. PMID: 21067463. DOI: 10.3109/10799893.2010.529577

16 Mann AP, Verma A, Sethi G, Manavathi B, Wang H, Fok JY, Kunnumakkara AB, Kumar R, Aggarwal BB and Mehta K: Overexpression of tissue transglutaminase leads to constitutive activation of nuclear factor-kappaB in cancer cells: Delineation of a novel pathway. Cancer Res 66(17): 8788-8795, 2006. PMID: 16951195. DOI: 10.1158/0008-5472.CAN-06-1457

17 Hunger SP, Lu X, Devidas M, Camitta BM, Gaynon PS, Winick NJ, Reaman GH and Carroll WL: Improved survival for children and adolescents with acute lymphoblastic leukemia between 1990 and 2005: A report from the children's Oncology Group. J Clin Oncol 30(14): 1663-1669, 2012. PMID: 22412151. DOI: 10.1200/ JCO.2011.37.8018

18 Litzow MR and Ferrando AA: How I treat T-cell acute lymphoblastic leukemia in adults. Blood 126(7): 833-841, 2015. PMID: 25966987. DOI: 10.1182/blood-2014-10-551895

19 Inukai T, Kiyokawa N, Campana D, Coustan-Smith E, Kikuchi A, Kobayashi M, Takahashi H, Koh K, Manabe A, Kumagai M, Ikuta K, Hayashi Y, Tsuchida M, Sugita K and Ohara A: Clinical significance of early T-cell precursor acute lymphoblastic leukaemia: Results of the Tokyo Children's Cancer Study Group study 199-15. Br J Haematol 156(3): 358-365, 2012. PMID: 22128890. DOI: 10.1111/j.1365-2141.2011.08955.x

20 Bond J, Graux C, Lhermitte L, Lara D, Cluzeau T, Leguay T, Cieslak A, Trinquand A, Pastoret C, Belhocine M, Spicuglia S, Lheritier V, Lepretre S, Thomas X, Huguet F, Ifrah N, Dombret $\mathrm{H}$, Macintyre E, Boissel $\mathrm{N}$ and Asnafi V: Early response-based therapy stratification improves survival in adult early thymic precursor acute lymphoblastic leukemia: A group for research on adult acute lymphoblastic leukemia study. J Clin Oncol 35(23): 2683-2691, 2017. PMID: 28605290. DOI: 10.1200/JCO.2016. 71.8585

21 Griffin M, Casadio R and Bergamini CM: Transglutaminases: Nature's biological glues. Biochem J 368(Pt 2): 377-396, 2002. PMID: 12366374. DOI: 10.1042/BJ20021234
22 Hodges LM, Markova SM, Chinn LW, Gow JM, Kroetz DL, Klein TE and Altman RB: Very important pharmacogene summary: ABCB1 (MDR1, P-glycoprotein). Pharmacogenet Genomics 21(3): 152-161, 2011. PMID: 20216335. DOI: 10.1097/ FPC.0b013e3283385a1c

23 Donnenberg VS and Donnenberg AD: Multiple drug resistance in cancer revisited: The cancer stem cell hypothesis. J Clin Pharmacol 45(8): 872-877, 2005. PMID: 16027397. DOI: $10.1177 / 0091270005276905$

24 Petriz J and Garcia-Lopez J: Flow cytometric analysis of Pglycoprotein function using rhodamine 123. Leukemia 11(7): 1124-1130, 1997. PMID: 9205001. DOI: 10.1038/sj.leu.2400659

25 Chaudhary PM and Roninson IB: Expression and activity of Pglycoprotein, a multidrug efflux pump, in human hematopoietic stem cells. Cell 66(1): 85-94, 1991. PMID: 1712673. DOI: 10.1016/0092-8674(91)90141-k

26 Chaudhary PM, Mechetner EB and Roninson IB: Expression and activity of the multidrug resistance P-glycoprotein in human peripheral blood lymphocytes. Blood 80(11): 2735-2739, 1992. PMID: 1360267. DOI: 10.1182/blood.V80.11.2735.2735

27 Neyfakh AA, Serpinskaya AS, Chervonsky AV, Apasov SG and Kazarov AR: Multidrug-resistance phenotype of a subpopulation of T-lymphocytes without drug selection. Exp Cell Res 185(2): 496505, 1989. PMID: 2480910. DOI: 10.1016/0014-4827(89)90318-2

28 Baldwin AS: Control of oncogenesis and cancer therapy resistance by the transcription factor nf-kappab. J Clin Invest 107(3): 241246, 2001. PMID: 11160144. DOI: 10.1172/JCI11991

29 Packham G: The role of nf-kappab in lymphoid malignancies. $\mathrm{Br}$ J Haematol 143(1): 3-15, 2008. PMID: 18573107. DOI: 10.1111/j.1365-2141.2008.07284.x

30 Naugler WE and Karin M: NF-kappaB and cancer-identifying targets and mechanisms. Curr Opin Genet Dev 18(1): 19-26, 2008. PMID: 18440219. DOI: 10.1016/j.gde.2008.01.020

31 Kim DS, Park SS, Nam BH, Kim IH and Kim SY: Reversal of drug resistance in breast cancer cells by transglutaminase 2 inhibition and nuclear factor-kappaB inactivation. Cancer Res 66(22): 10936-10943, 2006. PMID: 17108131. DOI: 10.1158/ 0008-5472.CAN-06-1521

32 Verma A and Mehta K: Transglutaminase-mediated activation of nuclear transcription factor-kappaB in cancer cells: A new therapeutic opportunity. Curr Cancer Drug Targets 7(6): 559-565, 2007. PMID: 17896921, DOI: 10.2174/156800907781662275

33 Lindsay MA, Bungay PJ and Griffin M: Transglutaminase involvement in the secretion of insulin from electropermeabilised rat islets of Langerhans. Biosci Rep 10(6): 557-561, 1990. PMID: 1707691. DOI: $10.1007 / \mathrm{bf01116616}$

34 Yeruva L, Hall C, Elegbede JA and Carper SW: Perillyl alcohol and methyl jasmonate sensitize cancer cells to cisplatin. Anticancer Drugs 21(1): 1-9, 2010. PMID: 19820395. DOI: 10.1097/CAD.0b013e32832a68ad

35 Meister S, Frey B, Lang VR, Gaipl US, Schett G, SchlotzerSchrehardt U and Voll RE: Calcium channel blocker verapamil enhances endoplasmic reticulum stress and cell death induced by proteasome inhibition in myeloma cells. Neoplasia 12(7): 550561, 2010. PMID: 20651984. DOI: 10.1593/neo.10228

Received September 25, 2019 Revised October 23, 2019 Accepted October 24, 2019 